\title{
Type IV SCCmec Found in Decade Old Brazilian MRSA Isolates
}

Cristina Reinert ${ }^{1}$, John Anthony McCulloch ${ }^{1}$, Shinya Watanabe ${ }^{2}$, Teruyo Ito $^{2}$, Keiichi Hiramatsu ${ }^{2}$ and Elsa Masae Mamizuka ${ }^{1}$ ${ }^{1}$ Department of Clinical Analysis, Pharmaceuthical Medical School, University of São Paulo; São Paulo, SP, Brazil; ${ }^{2}$ Department of Bacteriology, Juntendo University; Tokyo, Japan

\begin{abstract}
Methicillin-resistant Staphylococcus aureus (MRSA) commonly causes infection in hospitalized patients. Since its appearance in the 1960s, the SCCmec has evolved throughout the years into 5 different types (I-V), each bearing a different set of genes. Infection with MRSA SCCmec types I, II or III is almost exclusively restricted to hospitalised patients. However, recently, community acquired MRSA (CA-MRSA) infections have been reported with increasing frequency, usually caused by a type IV SCCmec MRSA in nosocomial settings. We studied the prevalence of SCCmec types in 50 nosocomial strains collected from 1995 to 1999. The SCCmec complex type and presence of PantonValentine leukocidin (PVL) were determined by PCR. Strains had been previously typed by PFGE and were now typed by MLST. We found that 3 of the isolates studied bore a type IVc SCCmec all having different PFGE and MLST profiles (ST3, ST5 and ST88). All strains bearing a type III SCCmec belonged to MLST ST239 (Brazilian/Iberian clone). Only the strain which presented the ST5 profile bore the pvl gene. The type IVc SCCmec strains presented relatively lower levels of resistance to oxacillin in comparison to the type III SCCmec strains. The pattern of dissemination of the type IV SCCmec remains to be elucidated. The finding of strains carrying a type IV SCCmec in the present study among strains isolated at least 7 years ago indicates that clones bearing a type IV SCCmec have been present in Brazil for quite some time, and must have gone by undetected.
\end{abstract}

Key-Words: Nosocomial infections, type IV SCCmec, Staphylococcus aureus, methicillin-resistant, Brazil.

Methicillin-resistant Staphylococcus aureus (MRSA) has established itself as one of the most important nosocomial pathogens in that it is expressively prevalent in the hospital environment and poses a challenge to antibiotic chemotherapy due to its multi-resistant profile. MRSA commonly causes infection in hospitalized patients who possess risk factors for the acquisition of this pathogen [1]. Methicillin resistance in $S$. aureus is conferred by the mecA gene, which is itself carried in a mobile genetic element called the staphylococcal cassette chromosome mec (SCCmec) [2]. Since its appearance in the 1960s, the SCCmec has evolved throughout the years into 5 different types (I-V), each bearing a different set of genes. Until recently, infection with MRSA was an event almost exclusively restricted to hospitalised patients, with most nosocomial MRSA strains bearing one of three types of SCCmec, either type I, II or III [3]. However, MRSA community infections have been reported with increasing frequency [4-6]. These infections, which are clinically similar to the ones caused by methicillin susceptible S. aureus (MSSA), usually affect individuals who do not bear the risk factors for the acquisition of MRSA [7]. Strains causing these infections are designated community acquired MRSA or CA-MRSA. These strains are usually more susceptible to antibiotics of different classes than their nosocomial counterparts and are represented by a larger number of different clones [7-9].

Received on 16 December 2007; revised 28 March 2008.

Address for correspondence: Dr. Cristina Reinert. Departamento de Análises Clínicas, Faculdade de Ciências Farmacêuticas, Universidade de São Paulo, Avenida Professor Lineu Prestes, 580 B17, 05508-900, São Paulo, SP, Brazil. Phone: (+5511) 3091-3663. Fax: (+5511) 38132197. E-mail: reinert@usp.br.

The Brazilian Journal of Infectious Diseases 2008;12(3):213-216. (C) 2008 by The Brazilian Journal of Infectious Diseases and Contexto Publishing. All rights reserved.
The CA-MRSA strains possess a SCCmec type designated type IV, which is physically smaller than the other SCCmec types and does not carry antimicrobial resistance genes other than the mecA gene [10]. They are usually more virulent than nosocomial MRSA, which, combined with their resistance to beta-lactams turns them into a menace, for infection can be fatal as has been previously reported [4].

An endemic MRSA clone has been shown to be widely disseminated throughout Brazilian hospitals. This clone is known as the Brazilian Endemic Clone (BEC) and has also been found to be disseminated elsewhere in South America, as well as in Europe [11,12]. This well characterised clone has been described as ST239 when typed by Multilocus Sequence Typing (MLST) [13], and carries a type III SCCmec [14]. Previous studies [15-17] describing the prevalence and extension of geographic dissemination of this single MRSA clone in Brazil showed it to represent close to $80 \%$ of MRSA isolates. This clone was reported as being the most frequent among MRSA isolates recovered from several hospitals from several cities located throughout Brazil's enormous territory and separated by a distance of several thousand kilometres. Souza et al. [11] also reported the predominance (97\%) and persistence of this clone among isolates in Brazil. Using Pulsed Field Gel Electrophoresis (PFGE), the BEC has been broken down into different subtypes all related to one another [11], which could be explained by its maintenance in Brazil at least since 1990 [17].

\section{Material and Methods}

Bacterial Isolates

The bacterial strains used in this study were selected from a collection obtained in a previous study [18] lasting four years (1995 to 1999), in which approximately 300 MRSA strains were collected in a multi-centre investigation involving 27 hospitals in several Brazilian cities. The strains were isolated 
from different human clinical samples, from colonization or infection without duplication of single patient, and were characterized by PFGE using SmaI, taking into consideration the criteria proposed by Tenover [19]. Approximately $80 \%$ of the isolates belonging to this collection had presented the same profile by PFGE (considered to be the BEC), whereas the remainder presented another 9 different profiles.

For the present study, 50 strains were selected from this collection in order to represent the 10 different PFGE clones found by Oliveira et al. [18] These 9 remaining clones presented a more susceptible profile to antibiotics when compared to BEC. Isolates were tested for resistance to oxacillin and vancomycin using the agar dilution method according to the Clinical and Laboratory Standard Institute (CLSI, formerly NCCLS) guidelines [20].

\section{Determination of SCCmec Complex}

The SCCmec complex type was determined by polymerase chain reaction (PCR). The primers used for the classification of type IV SCCmec into IVa and IVb subtypes were most kindly provided by Dr. T. Ito [10]. For determining SCCmec subtype IVc, primers IVcF (5'tctattcaatcgttctcgtattt-3') and IVcR (5'tcgttgtcatttaattctgaact-3’), also provided by Dr. Ito, were used as described previously [10].

\section{MLST}

MLST was performed as described previously [21] in order to determine the lineage of some strains.

\section{Determination of the PVL Gene}

Presence of the $p v l$ gene, which codes for PVL (suggested as a marker for type IV SCCmec) [22], was determined by using specific primers as previously described [23]. Strain MR108 was used as a positive control for this reaction.

\section{Results}

The types of SCCmec found for each strain as well as MLST strain type are described in Table 1 . The majority of strains presented a type III SCCmec. Three isolates bore a type IVc SCCmec, all having different PFGE profiles. The three type IVc SCCmec strains had been isolated from clinical specimens obtained from a navel abscess, from a surgical wound secretion and from pleural fluid. As expected, isolates carrying a type IVc SCCmec showed resistance to a lower number of antimicrobial agents belonging to different classes, compared to the other type III SCCmec strains and seemed not to be genetically related.

All strains bearing a type III SCCmec were typed by MLST as belonging to ST239, which is the profile of the BEC. The strains bearing a type IVc SCCmec, all presented profiles different to that of the BEC. These strains were characterised as ST3, ST5 and ST88. Of these strains, only the strain which presented the ST5 profile bore the $p v l$ gene.

\section{Discussion}

The type IVc SCCmec ST3 and ST5 strains presented relatively lower levels of resistance to oxacillin (MICs of 8 and $64 \mathrm{mg} / \mathrm{mL}$, respectively) in comparison to the type III SCCmec strains, which presented MICs $>512 \mu \mathrm{g} / \mathrm{mL}$.

MLST grouped several different PFGE profiles (A, B, E, H, I, $\mathrm{K}$ and $\mathrm{M}$ ) into a single strain type (ST239), which indicates that MLST's discriminatory power may be lower than that of PFGE. ST239 could thus be broken down into 7 different lineages, which would be invaluable in regional or institutional epidemiological studies. However, MLST unambiguously relates these 7 PFGE profiles with other globally present strains. It thus seems that PFGE is a good technique to analyse a small number of isolates obtained during outbreaks occurring in hospitals or communities in a relatively short period of time (1 to 3 months), because its greater discriminatory power would ensure the detection of lateral transmission even between strains belonging to ST239 determined by MLST [24]. On the other hand MLST is an excellent tool for investigating the clonal evolution of MRSA. The low number of strains used in this study probably does not allow the assessment of the merits of comparisons of these two methods.

PVL has consistently been found in CA-MRSA strains, so much so that it has been proposed as an epidemiological marker for CA-MRSA strains [22]. Studies have shown the physiopathological involvement of PVL in skin infections and necrotising pneumonia [25,26]. Out of three type IVc SCCmec strains identified in this present study, only one bore the $p v l$ gene. This strain had been isolated from pleural fluid. Unfortunately we did not have the opportunity to follow this case. The other type IVc SCCmec strains found did not bear the $p v l$ gene and had been isolated from a surgical wound secretion and a navel abscess.

The finding of type IV SCCmec in nosocomial strains in Brazil should be, like the emergence of VISA [27], of great concern to the medical community. CA-MRSA is emerging as significant community pathogens, especially in previously healthy children who bear no recognizable risk factors. It is predominantly associated with skin and soft tissue infections (especially abscesses and cellulitis). When present, risk factors are generally similar to those for infection with MSSA [28]. Some CA-MRSA strains have entered the hospital environment and caused outbreaks of infection, which has led to difficulty in distinguishing these strains from traditional nosocomial ones. CA-MRSA strains usually bear genes for PVL, which is associated with furunculosis and necrotizing pneumonia, and sometimes possess other virulence genes such as those for toxic shock syndrome or exfoliative toxins [29]. The pattern of dissemination of the type IV SCCmec remains to be elucidated. Whether the flow of type IV SCCmec strains is greater from the community to the hospital environment or vice versa is still unknown and might be revealed in future studies. What also remains to be determined is whether it might give rise to other SCCmec types in the future by 
Table 1. Phenotypic and genotypic properties of MRSA strains from different inpatients.

\begin{tabular}{|c|c|c|c|c|c|c|}
\hline $\begin{array}{c}\text { PFGE } \\
\text { Type (n) } \\
\end{array}$ & Antibiotic resistance $^{a}$ & $\begin{array}{c}\text { Oxacillin } \\
\text { MIC }(\mu \mathrm{g} / \mathrm{mL})\end{array}$ & Allelic profile ${ }^{b}$ & ST & $\begin{array}{c}\text { SCCmec } \\
\text { type }\end{array}$ & pvl genes \\
\hline $\mathrm{B}(1)$ & Oxa, Sxt, Ery, Amp, Tob, Tet, Gen, Cip, Cli & 256 & $2-3-1-1-4-4-3$ & 239 & III & Absence \\
\hline $\mathrm{D}(1)$ & Oxa, Chl, Ery, Tob & 8 & $1-4-1-4-12-1-10$ & 5 & IVc & Presence \\
\hline $\mathrm{E}(1)$ & Oxa, Sxt, Chl, Ery, Amp, Tob, Tet, Gen, Cip, Cli & $>512$ & $2-3-1-1-4-4-3$ & 239 & III & Absence \\
\hline $\mathrm{H}(1)$ & Oxa, Sxt, Ery, Amp, Tob, Tet, Gen, Cip, Cli & $>512$ & $2-3-1-1-4-4-3$ & 239 & III & Absence \\
\hline $\mathrm{I}(1)$ & Oxa, Sxt, Ery, Amp, Tob, Tet, Gen, Cli & $>512$ & $2-3-1-1-4-4-3$ & 239 & III & Absence \\
\hline $\mathrm{J}(1)$ & Oxa, Chl, Ery, Amp, Tob, Gen & $>512$ & 22-1-14-23-12-4-31 & 88 & IVc & Presence \\
\hline $\mathrm{K}(1)$ & Oxa, Sxt, Ery, Amp, Tob, Tet, Gen, Cip, Cli & $>512$ & $2-3-1-1-4-4-3$ & 239 & III & Absence \\
\hline $\mathrm{L}(1)$ & Oxa, Sxt, Ery, Amp, Tet & 64 & $1-1-1-9-1-1-12$ & 3 & IVc & Absence \\
\hline $\mathrm{M}(1)$ & Oxa, Sxt, Chl, Ery, Amp, Tob, Tet, Gen, Cip, Cli & 256 & 2-3-1-1-4-4-3 & 239 & III & Absence \\
\hline
\end{tabular}

aAntibiotics used: Oxa=oxacillin; Van=vancomycin; Sxt=sulphamethoxazole-trimethoprim; Chl=cloranphenicol; Ery=erythromycin; Amp=ampicillin;

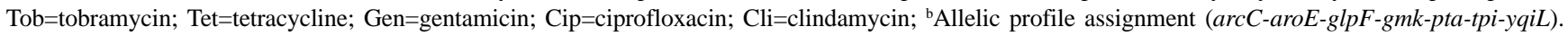

gaining or losing some of its genes. Indeed, other SCCmec types (V) have already been described. Whether these new types evolved from the type IV SCCmec or from the other older types (I to III) is still unknown.

Recently, a case of CA-MRSA strains isolated from a community infection in Brazil was reported [30]. The finding of strains carrying a type IV SCCmec in the present study among strains isolated at least 7 years ago, and moreover the report of a recent outbreak of type IV SCCmec strains at a Brazilian university hospital, reported by Trindade et al. [31], indicates that clones bearing a type IV SCCmec have been present in Brazil for quite some time, and must have escaped undetected. These strains are disseminating in hospitals where they may be adapting to vanquish the intense antimicrobial selective pressure present in a nosocomial environment. The detection and monitoring of strains carrying a type IV SCCmec in both hospital and community environments is crucial if we are to better understand their epidemiology and ultimately control their dissemination.

\section{Acknowledgements}

We thank the Conselho Nacional de Pesquisa (CNPq) for financial support.

\section{References}

1. Okuma K., Kozue I., Turnidge J.D. Dissemination of new Methicillin-resistant Staphylococcus aureus clones in the community. J Clin Microbiol 2002;40:4289-94.

2. Chambers H.F. The changing epidemiology of Staphylococcus aureus? Emerg Infect Dis 2001;7:135-6.

3. Ito T., Hiramatsu K. Structural comparison of three types of Staphylococcal cassette chromosome mec integrated in the chromosome in methicillin-resistant Staphylococcus aureus. Antimicrob Agents Chemother 2001;45:1323-36.

4. Hunt C., Dionne M., Delorme M., et al. Four pediatric deaths from community-acquired methicillin-resistant Staphylococcus aureus - Minnesota and North Dakota, 1997-1999. MMWR Morb Mortal Wkly Rep 1999;48:707-10.

5. Stacey A., Burden P., Croton G., et al. Contamination of television sets by methicillin-resistant Staphylococcus aureus (MRSA). J Hosp Infect 1998;39:243-4.
6. Zinderman C.E., Conner B., Malakooti M.A., et al. Communityacquired Methicillin-resistant Staphylococcus aureus among Military recruits. Emerg Infect Dis 2003;10:941-4.

7. Baba T., Takeuchi F., Kuroda M., et al. Genome and virulence determinants of high virulence community-acquired Staphylococcus aureus. Lancet 2002;359:1819-21.

8. Daum R.S., Ito T., Hiramatsu K., et al. A novel methicillin-resistance cassette in community-acquired methicillin resistant Staphylococcus aureus isolates of diverse genetic background. J Infect Dis 2002; 186:1344-7.

9. O’Brien F.G., Lim T.T., Chong F.N., et al. Diversity among Community Isolates of Methicillin-Resistant Staphylococcus aureus in Australia. J Clin Microb 2004;42:3185-90.

10. Ма X.X., Ito T., Tiensasitorn C., et al. Novel type of Staphylococcal Cassette Chromosome mec identified in community-acquired methicillin-resistant Staphylococcus aureus strains. Antimicrob Agents Chemother 2002;46:114752.

11. Souza M.A., Miragaia M., Sanches H.S., et al. Three-year assessment of methicillin-resistant Staphylococcus aureus clones in Latin America from 1996 to 1998. J Clin Microbiol 2001;39:2197-205.

12. Senna J.P.M., Pinto C.A., Mateos S., et al. Spread of a dominant methicillin-resistant Staphylococcus aureus (MRSA) clone between Uruguayan and South of Brazil Hospitals. J Hosp Infect 2003;53:156-7.

13. Robinson D.A., Enright M.C. Evolutionary models of the emergence of methicillin-resistant Staphylococcus aureus. Antimicrob Agents Chemoter 2003;47:3926-34.

14. Oliveira D.C., De Lencastre H. Multiplex PCR strategy for rapid identification of structural types and variants of the mec element in methicillin-resistant Staphylococcus aureus. Antimicrob Agents Chemother 2002;46:2155-61.

15. Santos Soares M., Silva-Carvalho M.C., Ferreira-Carvalho B.T., Figueiredo A.M. Spread of methicillin-resistant Staphylococcus aureus belonging to the Brazilian epidemic clone in a general hospital and emergence of heterogeneous resistance to glycopeptide antibiotics among these isolates. J Hosp Infect 2000; 44 :301-8.

16. Ramos R.L., Teixeira L.A., Ormonde L.R., et al. Emergence of mupirocin resistance in multiresistant Staphylococcus aureus clinical isolates belonging to Brazilian epidemic clone III::B::A. J Med Microbiol 1999;48:303-7.

17. Sader H.S., Pignatari A.C., Hollis R.J., Jones R.N. Evaluation of interhospital spread of methicillin-resistant Staphylococcus aureus in São Paulo, Brazil, using pulsed-field gel electrophoresis of chromossomal DNA. Rev Saude Publ 1994;28:406-9. 
18. Oliveira G.A., Faria J.B., Levy C.E., Mamizuka E.M. Characterization of the Brazilian endemic clone of methicillinresistant Staphylococcus aureus (MRSA) from hospitals throughout Brazil. Braz. J Infect Dis 2001;5:163-70.

19. Tenover F.C., Arbeit R.D., Goering R.V., et al. Interpreting chromossomal DNA restriction patterns produced by pulsedfield gel electrophoresis: criteria for bacterial strains typing. J Clin Microbiol 1995;33:2233-9.

20. NCCLS. M100-S11. National Committee for Clinical Laboratory Standards, Wayne, Pa, 2002.

21. Enright M.C., Day N.P., Davies C.E., et al. Multilocus sequence typing for characterization of methicillin-resistant and methicillin-susceptible clones of Staphylococcus aureus. J Clin Microbiol 2000;38:1008-15.

22. Vandenesch F., Naimi T., Enright M.C., et al. Community-acquired methicillin resistant Staphylococcus aureus carrying PantonValentine leukocidin genes: worldwide emergence. Emerg Infect Dis 2003;9:978-84.

23. Jarraud S., Mougel C., Thiolouse J., et al. Relationships between Staphylococcus aureus genetic background virulence factors, agr groups (Alleles), and human disease. Infect Immun 2002;70:631-41.

24. Olive D.M., Bean P. Principles and applications of methods for DNA-based typing of microbial organisms. J Clin Microbiol 1999;37:1661-9.
25. Gillet Y., Issarte B. Association between Staphylococcus aureus strains carrying gene for PVL and highly lethal necrotising pneumonia in young immunocompetent patients. Lancet 2002;359:753-9.

26. Lina G., Piemont Y., Godail-Gamot, F., et al. Involvement of Panton Valentine leukocidin producing Staphylococcus aureus in primary skin infections and pneumonia. Clin Infect Dis 1999;29:1128-32.

27. Oliveira G.A., Dell'Aquila M.A., Masiero R.L., et al. 2001a. Isolation in Brazil of nosocomial Staphylococcus aureus with reduced susceptibility to vancomycin. Infect Control Hosp Epidemiol 2001;22:443-8.

28. Eady E.A., Cove J.H. Staphylococcal resistance revisited community-acquired methicillin resistant Staphylococcus aureus - an emerging problem for the management of skin and soft tissue infections. Curr Opin Infect Dis 2003;16:103-24.

29. Gosbell I.B. Epidemiology, clinical features and management of infections due to community methicillin-resistant Staphylococcus aureus (cMRSA). Intern Med J 2005;35:120-35.

30. Ribeiro A., Dias C., Silva-Carvalho M.C., et al. First report of infection with community-acquired methicillin-resistant Staphylococcus aureus in South America. J Clin Microbiol 2005;43:1985-8.

31. Trindade P.A., Pacheco R.L., Costa S.F., et al. Prevalence of SCCmec type IV in nosocomial bloodstream isolates of methicillin-resistant Staphylococcus aureus. J Clin Microbiol 2005;43:3435-7. 